\title{
Normocalcaemic tetany
}

\author{
V Sehgal, S Vijayan, S Yasmin, U Srirangalingam, J Pati and WM Drake
}

\section{Case presentation}

A 71-year-old female, with a known history of transitional cell carcinoma of the bladder, presented acutely with abdominal pain, intractable vomiting and carpopedal spasm. She was awaiting a radical cystectomy as treatment for bladder carcinoma. Past medical history included asthma, chronic renal impairment and a previous ileal resection for Crohn's disease with a normal bowel habit. Medication on admission included mesalazine, lansoprazole, adcal D3 and a sodium cromoglicate inhaler. On examination she appeared in obvious distress with intense carpopedal spasm. She was apyrexial, tachycardic and hypotensive with a blood pressure of 93/54 $\mathrm{mmHg}$. Clinically she appeared hypovolaemic with a poor urine output. Chvostek's sign was positive. Trousseau's test was not performed as the patient was spontaneously in carpopedal spasm; the remainder of the examination was non-contributory. Baseline investigations at admission are demonstrated in Box 1. Her baseline creatinine was known to be $228 \mu \mathrm{mol} / \mathrm{l}$.

\section{What is the differential diagnosis and the most likely diagnosis?}

The differential diagnoses initially considered in this subject included bowel obstruction, inflammatory bowel disease, acute on chronic renal failure and pancreatitis. Carpopedal spasm suggested the presence of hypocalcaemia. Bowel obstruction was deemed most likely given the clinical presentation, possibly a consequence of adhesions following previous ileal resection. An inflammatory bowel disease flare was considered but her disease had been quiescent and there was no associated change in bowel habit. Acute renal failure may have been precipitated due to hypovolaemia or outflow obstruction, potentially relating to transitional cell carcinoma of the bladder. A diagnosis of pancreatitis would link the abdominal symptoms with carpopedal spasm (hypocalcaemia).

\section{What is the initial management?}

The patient was made nil-by-mouth and a nasogastric tube was inserted. An antiemetic was given and fluid resuscitation

V Sehgal, ${ }^{1}$ senior house officer; S Vijayan, ${ }^{1}$ house officer; S Yasmin, ${ }^{1}$ house officer; U Srirangalingam, ${ }^{1}$ specialist registrar; ] Pati, ${ }^{2}$ consultant urologist; WM Drake, ${ }^{1}$ consultant endocrinologist

${ }^{1}$ Department of Endocrinology, ${ }^{2}$ Department of Urology

St Bartholomew's Hospital, London instigated. Serum amylase and abdominal film were unremarkable. Despite carpopedal spasm the patient was normocalcaemic (corrected calcium $2.44 \mathrm{mmol} / \mathrm{l}$ ) with a serum phosphate at the upper limit of normal $(1.53 \mathrm{mmol} / \mathrm{l})$ and a normal alkaline phosphatase (66 IU/l). She initially received two litres of normal saline $(0.9 \%)$ followed by four litres of Hartmann's solution over the initial 36-hour period. Her haemodynamic status improved but the episodes of tetany and carpopedal spasm continued. An arterial blood sample was obtained. This demonstrated a profound metabolic and respiratory alkalosis with a $\mathrm{pH} 7.75$ (7.35-7.45), $\mathrm{pCO}_{2} 3.33 \mathrm{kPa}(4.7-6.0 \mathrm{kPa}), \mathrm{p}_{2} 12.9 \mathrm{kPa}$ $(>10.6 \mathrm{kPa}), \mathrm{HCO}_{3}{ }^{-} 39.5 \mathrm{mmol} / \mathrm{l}(22-29 \mathrm{mmol} / \mathrm{l})$ and $\mathrm{Cl}^{-}$ $86 \mathrm{mmol} / \mathrm{l}(98-106 \mathrm{mmol} / \mathrm{l})$. Calcium gluconate $(10 \%)$ was administered intravenously and was associated with a cessation of symptoms. A repeat corrected calcium was in the upper half of the normal range. However further episodes of carpopedal spasm ensued. An endocrine opinion was requested.

\section{Case progression}

Review of the case and investigations identified the cause of the carpopedal spasm to be the low-ionised calcium of $0.96 \mathrm{mmol} / \mathrm{l}$ $(1.0-1.25 \mathrm{mmol} / \mathrm{l})$ presumed to be consequent on the profound alkalosis in the context of hyperemesis. This was exacerbated by the administration of Hartmann's solution on a background of acute renal impairment. It is likely that the ionised calcium was initially lower than this as the first measurement occurred after the administration of intravenous calcium. A respiratory alkalosis was an unexpected finding in the presence of a metabolic alkalosis. Investigations excluded a pulmonary embolus. This component was attributed to hyperventilation at the time of her acute illness.

Further fluid resuscitation with normal saline was recommended. Administration of a calcium gluconate was advised in order to terminate further episodes of tetany. The patient

\section{Box 1. Results of baseline investigations.}

$\begin{array}{lll}\text { Haemoglobin } & 10.2 \mathrm{~g} / \mathrm{dl} & (11.5-16.6 \mathrm{~g} / \mathrm{dL}) \\ \text { Mean corpuscular volume } & 89.4 \mathrm{fL} & (76-96 \mathrm{fL}) \\ \text { White cell count } & 11.5 \times 10^{9} / \mathrm{L} & \left(4.0-11.0 \times 10^{9} / \mathrm{L}\right) \\ \text { Sodium } & 146 \mathrm{mmol} / \mathrm{l} & (135-145 \mathrm{mmol} / \mathrm{l}) \\ \text { Potassium } & 4.5 \mathrm{mmol} / \mathrm{l} & (3.5-5.0 \mathrm{mmol} / \mathrm{l}) \\ \text { Urea } & 20.1 \mathrm{mmol} / \mathrm{l} & (2.5-6.4 \mathrm{mmol} / \mathrm{l}) \\ \text { Creatinine } & 373 \mu \mathrm{mol} / \mathrm{l} & (62-106 \mu \mathrm{mol} / \mathrm{l})\end{array}$


gradually improved clinically with a normalisation of the blood pressure, improving renal function (creatinine $210 \mu \mathrm{mol} / \mathrm{l}$ ), resolution of the alkalosis and no further tetany or carpopedal spasm. The precipitating cause of the vomiting was found to be due to extrinsic compression of the duodenum from an unrelated cause.

\section{Discussion}

This case highlights a subject with recurrent carpopedal spasm and tetany in the face of apparent normocalcaemia. Despite a normal total and corrected serum calcium, the presence of a low serum ionised calcium in the context of an extreme mixed alkalosis and acute prerenal failure precipitated her symptoms.

Total serum calcium consists of free or ionised calcium (50\%), calcium bound to protein (40\%), principally albumin, and calcium coupled with anions (10\%), eg lactate, bicarbonate. Unlike total serum calcium, ionised calcium is unaffected by albumin concentration but varies according to disturbances in acid-base balance. $\mathrm{H}^{+}$ions compete with calcium to bind albumin. Thus acidotic states result in increased free/ionised calcium and alkalotic states conversely, a decreased ionised calcium. Acute hypocalcaemia may manifest with neuromuscular symptoms of circumoral and digital paraesthesiae, tetany, bronchospasm and cardiovascular instability and is a medical emergency.

The typical acid-base derangement in renal failure is that of a metabolic acidosis. In this case, a metabolic alkalosis was consequent upon a combination of vomiting and injudicious use of Hartmann's solution. One litre of Hartmann's solution (sodium lactate) typically contains $29 \mathrm{mmol} / \mathrm{l}$ of lactate which is converted to bicarbonate via pyruvate in an equimolar concentration. Above a threshold of $24 \mathrm{mmol} / \mathrm{l}$, the kidney would excrete bicarbonate proportionally to the filtration rate. ${ }^{1}$ In this particular case, however, prerenal failure and volume depletion led to a reduced filtered load of bicarbonate. Additional mechanisms are likely to have also contributed. Volume depletion, chloride depletion and secondary hyperaldosteronism all cause an increase in tubular bicarbonate reabsorption., ${ }^{2,3}$ The reabsorptive threshold of the tubules for bicarbonate may increase to $35 \mathrm{mmol} / \mathrm{l}$ with severe volume depletion, resulting in a marked alkalosis. ${ }^{4,5}$

Immediate relief from tetanic contractions was achieved by the administration of intravenous calcium gluconate. To achieve this it was envisaged that the corrected calcium would need to be temporarily raised above the upper limit of the normal range to secure a normal ionised calcium, until the metabolic alkalosis

\section{Key learning points}

- Acute hypocalcaemia is a medical emergency and unless treated promptly, may progress to bronchospasm and cardiovascular instability.

- Profound alkalosis may lower the ionised calcium resulting in tetany despite a normal corrected calcium.

- The corrected calcium may need to be raised above the normal range to maintain a normal ionised calcium in the context of metabolic alkalosis and tetany.

- To be aware of the contraindications and potential risks posed by the routine use of Hartmann's solution in clinical practice.

could be corrected. Substitution of Hartmann's solution with normal saline reduced bicarbonate loading, corrected her volume status and chloride depletion.

Hartmann's solution remains the fluid of choice for anaesthetists both in the intensive care and peri-operative setting who argue that its composition resembles plasma most accurately. Renal physicians have used lactate-based dialysis fluids for renal replacement therapies for many years. Contra-indications for Hartmann's solution include use in diabetes mellitus, alcoholic liver disease and renal impairment, the latter because of the inability to convert lactate to bicarbonate. ${ }^{6}$ In this case, given the significant acid-base derangement, Hartmann's solution would have been contraindicated. This case illustrates the potential risks of using Hartmann's solution as routine fluid replacement with an unusual clinic manifestation.

\section{References}

1 Pitts RF, Lotspeich WD. Bicarbonate and the renal regulation of acid base balance. Am J Physiol 1946;147:138-54.

2 Berger BE, Cogan MG, Sebastian A. Reduced glomerular filtration and enhanced bicarbonate reabsorption maintain metabolic alkalosis in humans. Kidney Int 1984;26:205-8.

3 Galla JH, Gifford JD, Luke RG, Rome L. Adaptations to chloridedepletion alkalosis. Am J Physiol 1991;261(4 Pt 2):R771-81.

4 Jacobson HR, Seldin DW. On the generation, maintenance, and correction of metabolic alkalosis. Am J Physiol 1983;245:F425-32.

5 Sabatini S, Kurtzman NA. The maintenance of metabolic alkalosis: factors which decrease bicarbonate excretion. Kidney Int 1984;25:357-61.

6 Thomas DJ, Alberti KG. Hyperglycaemic effects of Hartmann's solution during surgery in patients with maturity onset diabetes. $\mathrm{Br} J$ Anaesth 1978;50:185-8.

Address for correspondence: Dr V Sehgal, 28 Stansfield

Road, Hounslow, Middlesex TW4 7QR.

Email: vsehgal@doctors.org.uk 